\section{The Canadian Association of Gastroenterology position on colon cancer screening}

\author{
Desmond Leddin MB FRCPC \\ Chair, CAG Education Committee
}

$T^{\mathrm{h}}$ he long awaited report by $\mathrm{H}$ ealth $\mathrm{C}$ anada with recommendations for a national colon cancer screening program has just been published. For details, go the Health Canada Web site at www.hc-sc.gc.ca and search under cancer screening.

It recommen ds that a screening program be established based on fecal occult blood testing every two years of the population in the age range of 50 to 74 years. Colonoscopy, or flexible sigmoidoscopy and double contrast barium enema, should follow positive occult blood tests. The choice of follow-up test will depend on available local resources.

The $\mathrm{C}$ ommittee reached its final recommendations by following two processes. First, they conducted an extensive review of the available literature, and pointed out that the trial evidence for efficacy of screening tests is strongest for occult blood. Second, they employed a model developed by Statistics $\mathrm{C}$ anada called Population Health microsimulation Model (POHEM).

In POHEM an artificial population is synthesized. This population is given the characteristics of the real $C$ anadian population. The outcome parameters for the model were derived from a review of the literature, particularly the Funen trial in Denmark, the $\mathrm{M}$ innesota trial and the $\mathrm{N}$ ottingham trial of occult blood screening (1-3). The model parameters with regard to cancer characteristics were derived from various sources; some of these data are current, but some of them are more than a decade old. Expert input was also sought from physicians involved in the area. Dr Dan Sadowski, at the U niversity of A Iberta (Edmonton), provided expert assistance to the modeling panel and represented the $C$ anadian A ssociation of $\mathrm{G}$ astroenterology (CA G).

The strengths and weaknesses of the POHEM modelling, and of the recommendations, will be discussed in detail at the $\mathrm{C}$ anadian Digestive $\mathrm{H}$ ealth Foundation symposium, which will be held on the opening day of the $C$ anadian Digestive Diseases W eek (CDDW) in Banff, A lberta, February 19 to 25, 2003. The main weakness is that, like all models, the validity is dependent both on the assumptions used to construct the model and on whether those assumptions can be generalized to a different population. Extrapolating from a screening trial of 60,000 Danes to a synthetic cohort of 7.2 million $C$ anadians requires quite a leap of faith.

The main strength is that it gives us an idea of the benefit and cost that may be involved in setting up such a program. $0 \mathrm{n}$ the benefit side, there is little doubt that this is a serious problem. There will be approximately 17,000 new cases of colon cancer diagnosed in $C$ anada next year, with a mortality of approximately one third. The results of the $\mathrm{H}$ ealth $\mathrm{C}$ anada modelling, however, are not very encouraging. The estimated reduction in colorectal cancer mortali-

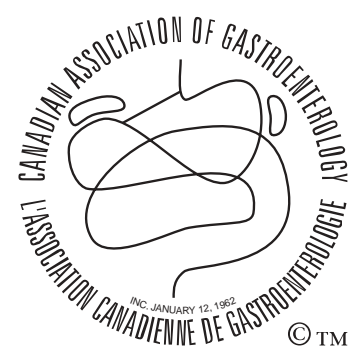

En français voir page 134

ty over 10 years would be about $16.7 \%$. In addition, it is estimated that the cost of treating colorectal cancer will decrease by about $5 \%$. This relatively small reduction in colorectal cancer mortality, and even smaller reduction in total cohort mortality, will be at the expense of an increase of 55,000 colonoscopies throughout the country, at an estimated total program cost of $\$ 120,000,000$ per year.

These numbers are difficult to translate into local impact, but a 'back of envelope' calculation can be done for your area. If we take a population of $1,000,000$, approximately 200,000 people will be between the ages of 50 and 75 years. Divide this in half, because it is a biennial program, and half the population will therefore be screened each year. Each year occult blood testing is offered to 100,000 people. A ssume that $70 \%$ of these will participate in a screening program. It follows that 70,000 occult blood tests are completed. A ssuming $2 \%$ are positive, this generates 1400 consultation and colonoscopy requests. Thirty consultations and the attendant colonoscopies would be a very reasonable week's work for a gastroenterologist. This translates into about 45 weeks, with 30 patients per week, or 1350 per year of the occult blood-positive patients seen and investigated by one full-time gastroenterologist. It follows that the proposed program will require the addition of a least 1.0 full time gastroenterologists per million population. A dditional nursing, pathology and radiology, and a significant amount of administrative support will also be needed. You can calculate the resources required if the positivity rate is $3 \%$ or $4 \%$ or the acceptance rate is $50 \%$.

Dr Richard Hunt of $\mathrm{M} \mathrm{CM}$ aster $\mathrm{U}$ niversity, $\mathrm{H}$ amilton, $\mathrm{O}$ ntario is leading the $C A G / C$ anadian Digestive $H$ ealth Foundation response to the $\mathrm{H}$ ealth $\mathrm{C}$ anada report. $\mathrm{Dr} \mathrm{H}$ unt has assembled a group of interested clinicians from both community- and hospital-based practices from across the country. The report in currently being analyzed in detail, and we hope that Dr H unt's group will make a final recommendation at $C D D W$ to the $C A G$ Executive Board with regard to whether the report should be endorsed by the $C A G$. In addition, $\mathrm{Dr} \mathrm{H}$ unt has requested that a series of practical guidelines be developed for distribution to CAG members and others. Guidance to clinicians will be available in the near future. In the interim, it is best to proceed cautiously.

\section{REFEREN CES}

1. Kronberg $O$, Fenger $C, O$ sen $J$, Jorgensen $O D$, Sondergaard $O$. Randomised study of screening for colorectal cancer with faecal-occult-blood test. Lancet 1996;348:1467-71.

2. Hardcastle JD, C hamberlain JO, Robinson MD, et al. Randomised controlled trial for faecal-occult-blood screening for colorectal cancer. Lancet 1996;348:1472-7.

3. M andel JS, Bond JH, Church TR, et al. Reducing mortality from colorectal cancer by screening for fecal occult blood. N Eng J M ed 1993;328:1365-71.
A bbott Laboratories $L$ td.
A straZeneca $\mathrm{C}$ anada Inc.
A xcan Pharma Inc.
Janssen-0 rtho Inc. 


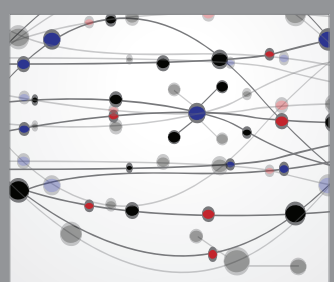

The Scientific World Journal
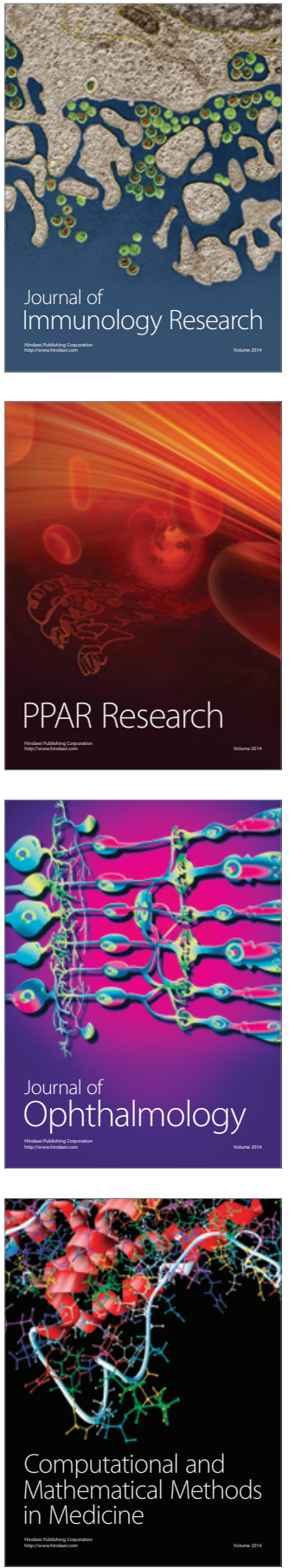

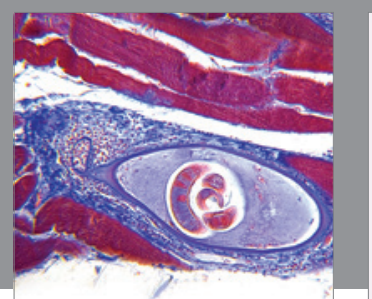

Gastroenterology Research and Practice

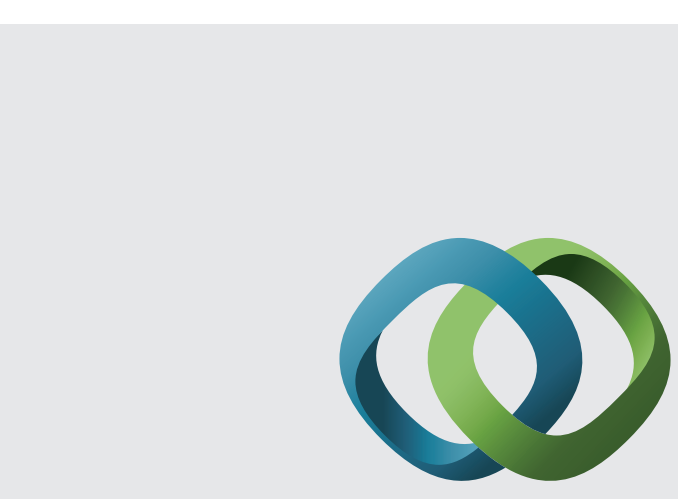

\section{Hindawi}

Submit your manuscripts at

http://www.hindawi.com
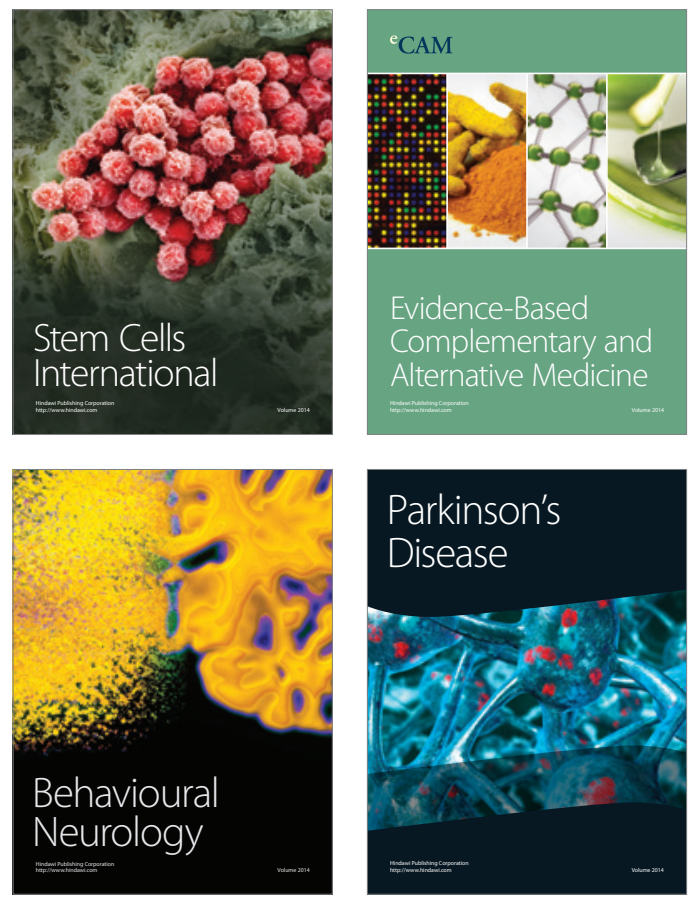
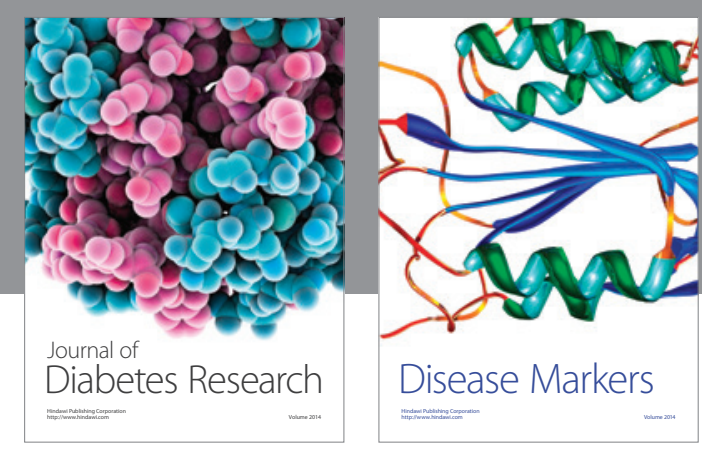

Disease Markers
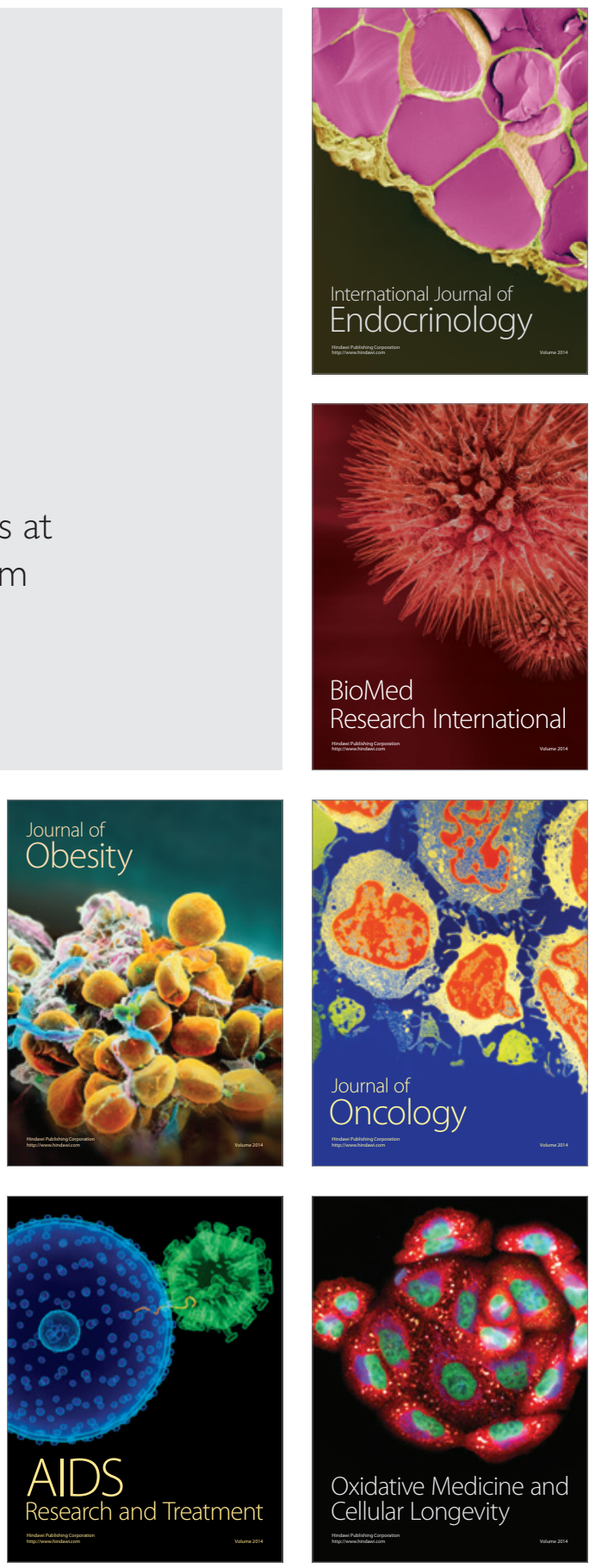